J. Clin. Chem. Clin. Biochem.

Vol. 25, 1987, pp. 805-809

(C) 1987 Walter de Gruyter \& Co.

Berlin - New York

\title{
New System of Continuous Monitoring of Enzyme Activities and Determination of Some Substrates
}

\author{
By J. Homolka \\ Department of Clinical Biochemistry, Faculty of General Medicine, Charles University, Prague, Czechoslovakia
}

(Received January 16/June 22, 1987)

Summary: The proposed system of continuous monitoring of enzyme activities is based primarily on the electrochemical behaviour of thiol compounds, and the experimental equipment is extremely simple. The determination of cholinesterase (EC 3.1.1.8) activity is described. The normal values obtained for men (73.9, $\mathrm{s} \pm 10.3 \mu \mathrm{kat} / \mathrm{l})$ and for women $(71.1, \mathrm{~s} \pm 10.2 \mu \mathrm{kat} / \mathrm{l})$, lie within the usual range of analogous photometric methods. Systems for determination of the activities of alkaline phosphatase (EC 3.1.3.1) and adenosylhomocysteinase (EC 3.3.1.1) are described. The activity of aspartate aminotransferase (EC 2.6.1.1) is determined by a combination of enzyme reactions, in which $\mathrm{CoA}$ is released from acetyl-CoA. Analogous procedures are discussed for determinations of alanine aminotransferase (EC 2.6.1.2), lactate dehydrogenase (EC 1.1.1.27), lipase (EC 3.1.1.2), and phospholipase $A_{2}$ (EC 3.1.1.4) activities, and for determination of substrates, e. g., acetate and carnitine. Possible determinations of an additional 199 enzyme activities and of some of substrates are suggested. By determining electrochemically active groups other than thiols this method becomes almost universally applicable.

\section{Introduction}

Photometric methods, universally recommended for determinations of enzyme activities, also have certain drawbacks. Above all, turbid or haemolytic materials are unusable; this means that very pure solutions of, e. g., auxiliary enzymes are required, which obviously are substantially more costly. Many methods require ultraviolet photometric equipment, disproportionately more costly than that described by us.

Our proposed method is based on an electrochemical principle, making use of the electrochemical behaviour of thiol compounds (1); consequently, the optical properties of the used solutions are of no importance. By combined enzyme reactions it is possible to determine the activities of a great number of enzymes, and the concentrations of certain substrates. In the following text we describe the continuous monitoring of cholinesterase activity and suggest the possibility of continuous monitoring of alkaline phosphatase, adenosylhomocysteinase, and aspartate aminotrans- ferase activities. Furthermore, the possibility of continuous monitoring of the activities of other enzymes and of determinations of some substrates is suggested.

\section{Materials and Methods}

Principle

In principle such substrates are used whose cleavage produces thiols, either directly, or in some cases only by combination of consecutive enzyme reactions. Thiols are easy to determine electrochemically, inducing anodic current on a mercury electrode by forming a compound with mercury. Thio compounds, e. g., thiocholine chloride, reduced glutathione, when determined electrochemically on the polarographic principle, have a half-wave potential $-0.15 \mathrm{~V}$ against a saturated mercurous sulphate electrode at $\mathrm{pH} 3.65$; along with increasing $\mathrm{pH}$ the half-wave potential shifts by $61 \mathrm{mV} / \mathrm{pH}$ toward higher negative values, and from $\mathrm{pH} 8.0$ onward the half-wave potential stabilizes at $-0.41 \mathrm{~V}(1)$. Consequently, in practice $\mathrm{pH}$ values from 3.65 to 10.0 , and stable potentials from $-0.15 \mathrm{~V}$ to $-0.41 \mathrm{~V}$, are usable. Therefore also the stable potential $-0.24 \mathrm{~V}$ of saturated calomel electrode is also useful, and we exploited this in our experimental instrumental design. To prevent the 
oxidative action of oxygen upon thiocholine chloride at the given potential, we displace oxygen by briefly bubbling nitrogen through the test solution. Oxidized thiocholine produces a cathodic wave, corresponding to the reduction of the disulphide bond; at $\mathrm{pH} 3.65$ it has a considerably higher half-wave potential $-0.32 \mathrm{~V}$; along with increasing $\mathrm{pH}$ values the half-wave potential shifts toward more negative values, and from $\mathrm{pH} 8.5$ onward it stabilizes at $-0.63 \mathrm{~V}$. The nitrogen atmosphere, very slow oxidation even in the presence of oxygen (1), and the different half-wave potential of disulphides ensure a true determination of the thiol groups.

\section{Apparatus}

The classical polarographic method is based on automatic recording and subsequent interpretation of curves expressing the dependence of the intensity of a current flowing through the analysed solution on its voltage, which is being constantly increased. The current flows from a dropping electrode, immersed in the analysed solution, to a reference electrode which is non-polarizable, i.e. it retains a constant potential even when the current is flowing.

Our method uses neither the classical form nor a polarographic instrument. A calomel electrode serves as the source of a suitable constant potential, and the recorded changes are caused by the diffuse current generated by the increasing concentration of thiols in the solution. The terms "half-wave potential" and "diffuse current" are explained in monographies on polarography and also in an earlier publication (2).

The experimental equipment (3) is shown in figure 1 . The essential part is a tempered modified cell according to Heyrovsky \& Kalousek (on the left in the figure), to which a calomel electrode is connected by a small-pore sintered glass (1G5 Jena Schott) junction. The bottom part of the cell includes an inlet of nitrogen, which bubbles through the liquid, stirring it and displacing oxygen from the solution. From the top a mercury dropping electrode, with a rate of one drop per 3 seconds, is inserted into the cell; its electric terminal, as well as that of the calomel electrode, are connected via a compensating resistor $(10 \mathrm{Ohm})$ with a compensating recorder LP EZ 2 (Laboratorni přistroje, Prague, $2 \mathrm{mV}$ sensitivity), and their leads are mutually connected via another resistor $(10 \mathrm{k} \Omega)$. Thus an electric current divider is produced with the ratio $1: 1000$.

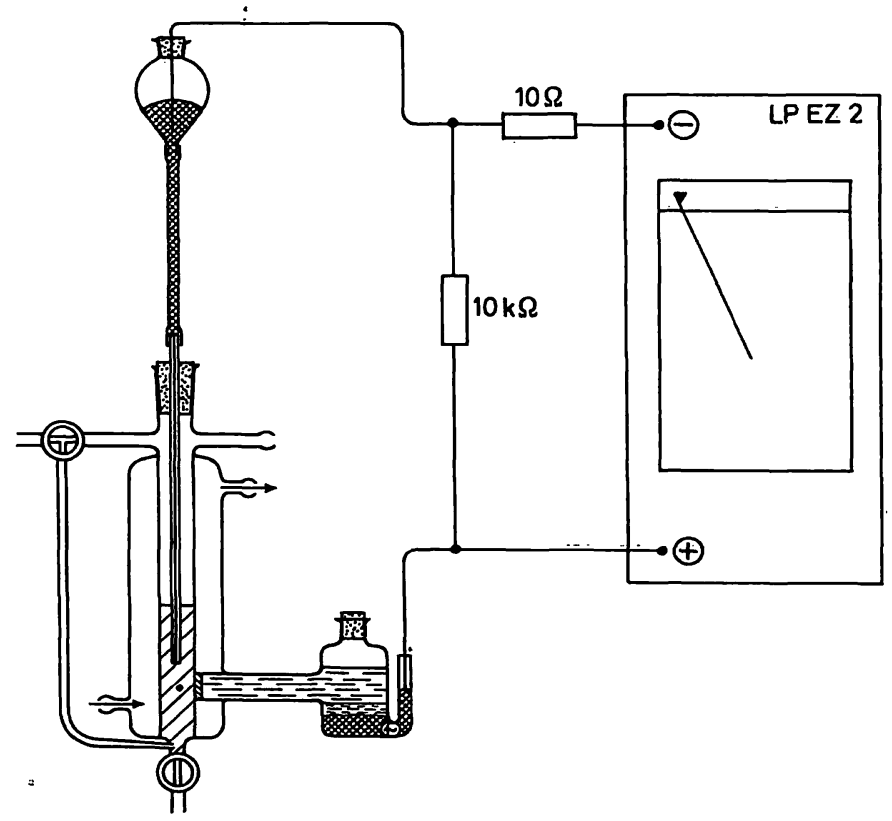

Fig. 1. Modified cell according to Heyrovský \& Kalousek for enzyme activity determinations, showing electric resistors and recorder. Explanation in text.

\section{Material}

We used blood or blood sera obtained in the same morning from outpatients and controls. For demonstrating pathological findings we used sera supplied on the same day from the wards.

\section{Reagents used}

Butyrylthiocholine chloride, pure, Koch-Light; glutathione, reduced, Loba; S-(4-methoxyphenyl)thiophosphate, Institute of Organic Chemistry, Czechoslovak Academy of Sciences; Sadenosyl- $L$-homocysteine, Serva; $L$-aspartate, 2 -oxoglutarate, and citrate synthase Boehringer, Mannheim, acetylcoenzyme A trilithium salt, Serva; and inorganic reagents, analytical grade, Merck.

Determination of cholinesterase activity (EC 3.1.1.8)

\section{Reagents}

Phosphate buffer solution, $1 / 15 \mathrm{~mol} / \mathrm{l}, \mathrm{pH} 8.0 ; 0.024 \cdot \mathrm{mol} / 1$ aqueous solution of butyrylthiocholine chloride; $2 \mathrm{mmol} / \mathrm{l} \mathrm{re}-$ duced glutathione aqueous solution.

\section{Procedure}

$2 \mathrm{ml}$ of phosphate buffer solution and $0.25 \mathrm{ml}$ of butyrylthiocholine chloride solution are pipetted into the cell, which is kept at $30^{\circ} \mathrm{C}$, and purged with nitrogen for $1-2$ minutes. Then the dropping mercury electrode is put into operation and the blank tracing is recorded, which is parallel with the recorder chart margin. Then $50 \mu \mathrm{l}$ of serum is added, nitrogen is bubbled through for another 20 seconds, and the enzyme activity course is traced on the recorder. This tracing has a slanted course, and its slope versus the blank tracing or its drop per time unit is a measure of enzyme activity. An example is shown in figure 2. If the result exceeds $70 \mu \mathrm{kat} / \mathrm{l}$, a lesser volume of serum has to be used, with appropriate calculation.

\section{Calibration}

$2 \mathrm{ml}$ of buffer solution and $0.3 \mathrm{ml}$ of reduced glutathione solution are pipetted into the cell, and the deviation versus the blank is determined. This corresponds to the formation of 0.6 $\mu \mathrm{mol} / 1$ thio groups from the serum sample, and on conversion indicates an activity of $12000 \mathrm{U} / \mathrm{l}$ or $200 \mu \mathrm{kat} / \mathrm{l}$.

The determination is feasible not only with serum, but also with heparinized blood, plasma, and haemolysate from erythro= cytes. An analogous procedure can be used with acetylthiocholine chloride as the substrate for the determination of so-called true acetylcholinesterase (EC 3.1.1.7), present mainly in erythrocytes.

Determination of alkaline phosphatase activity (EC 3.1.3.1) - demonstration of feasibility

\section{Reagents}

Carbonate-bicarbonate buffer solution $0.1 \mathrm{~mol} / 1 \mathrm{pH} 10.0$; substrate: S-(4-methoxyphenyl) thiophosphate $2 \mathrm{mmol} / 1$ solution in the foregoing buffer solution.

\section{Procedure}

$2 \mathrm{ml}$ of buffer solution and $0.25 \mathrm{ml}$ of substrate solution are pipetted into the cell. The procedure is completely analogous to the preceding determination, but $100 \mu$ of serum is added, with appropriate calculation. Figure 3 shows an example of this determination. Evidently a simpler analogous substrate might be used, but no such one was available to us. 


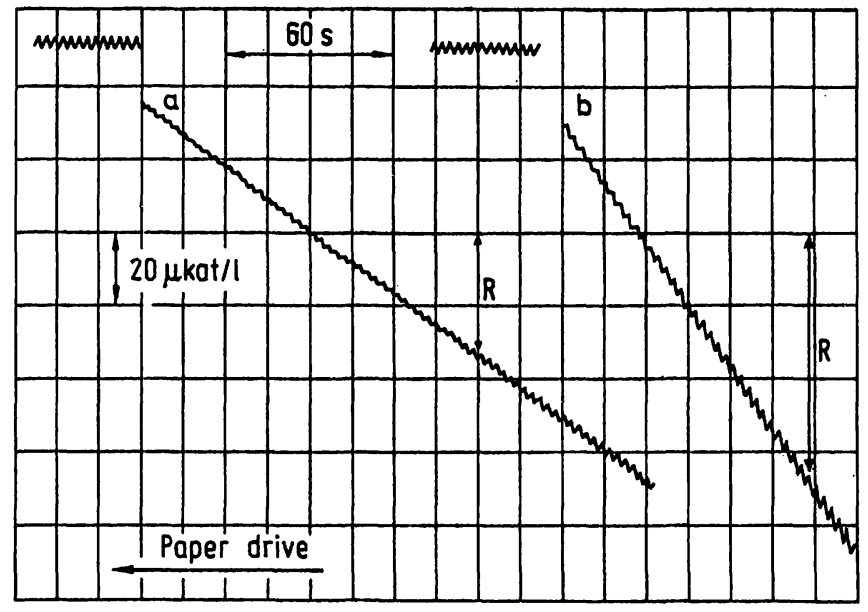

Fig. 2. Cholinesterase assay.

Horizontal tracings = blanks; $\mathrm{R}=$ resulting catalytic concentration in $\mu \mathrm{kat} / \mathrm{l}$; recording $\mathrm{a}=30.6 \mu \mathrm{kat} / \mathrm{l}$; recording $\mathrm{b}=64.7 \mu \mathrm{kat} / \mathrm{l}$.

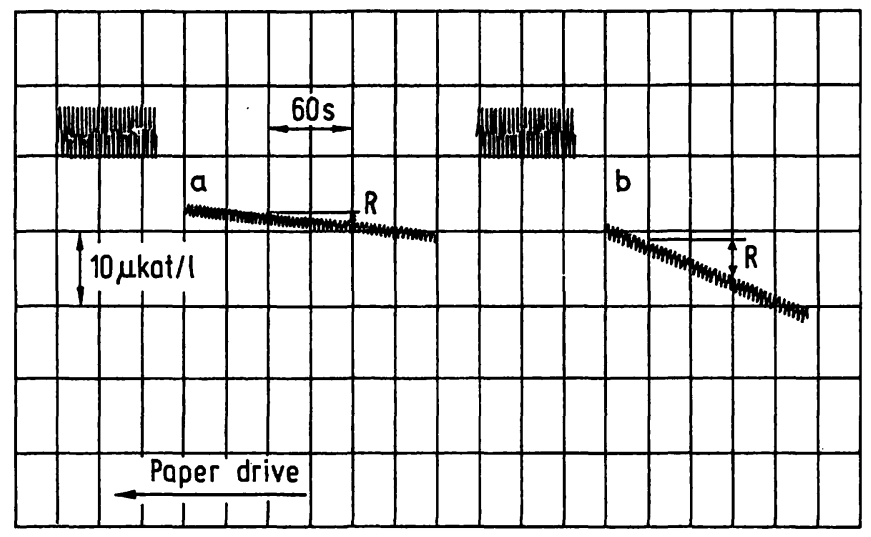

Fig. 3. Alkaline phosphatase assay.

Horizontal tracings = blanks; $\mathrm{R}=$ resulting catalytic concentration in $\mu \mathrm{kat} / \mathrm{l}$; recording $\mathrm{a}=1.14 \mu \mathrm{kat} / \mathrm{l}$; recording $\mathrm{b}=4.54 \mu \mathrm{kat} / \mathrm{l}$.

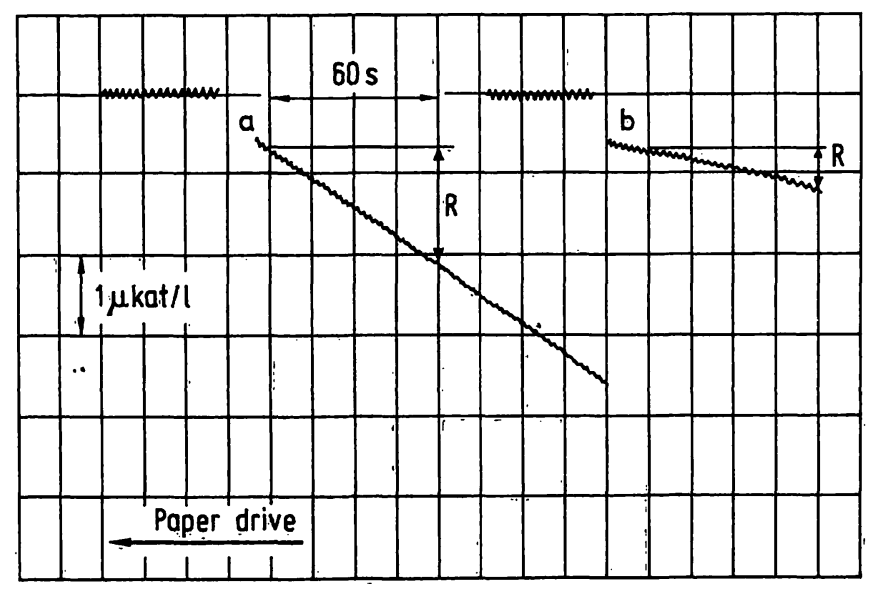

Fig. 4. Aspartate aminotransferase assay. Horizontal tracings $=$ blanks; $\mathbf{R}=$ resulting catalytic concentration in $\mu \mathrm{kat} / \mathrm{l}$; recording $\mathrm{a}=1.43 \mu \mathrm{kat} / \mathrm{l}$; recording $b=0.41 \mu \mathrm{kat} / \mathrm{l}$.
Determination of adenosylhomocysteinase activity (EC 3.3.1.1) - demonstration of feasibility

\section{Reagents}

Phosphate buffer solution 1/15 mol/l, pH 8.0; S-adenosyl-Lhomocysteine $240 \mu \mathrm{mol} / \mathrm{l}$ solution in the preceding buffer solution.

\section{Procedure}

$3 \mathrm{ml}$ of buffer solution and $1 \mathrm{ml}$ of substrate solution are pipetted into the cell. The procedure is analogous to the preceding determination, but $0.4 \mathrm{ml}$ of freeze-haemolysed blood is added. The generated homocysteine yiclds a tracing much similar to the preceding figures.

Determination of aspartate aminotransferase activity (EC 2.6.1.1) - demonstration of feasibility

The principle consists of a combination of enzyme reactions, in the course of which coenzyme $A$ is liberated from acetylcoenzyme A with thiol group formation (4). The reactions proceed as follows:

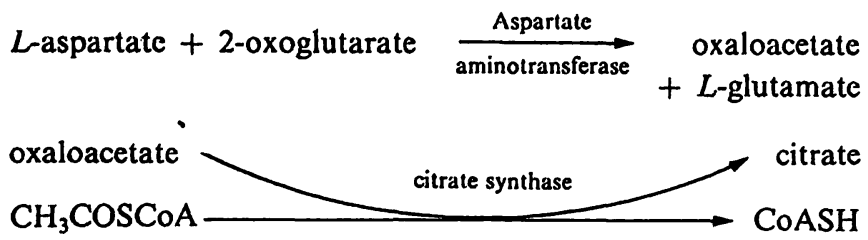

\section{Reagents}

Substrate solution containing in each litre of $0.1 \mathrm{~mol} / 1$ phosphate or another suitable buffer solution, pH 7.8, $170 \mathrm{mmol}$ $L$-aspartate, $15 \mathrm{mmol}$ 2-oxoglutarate, $25 \mathrm{mg}$ citrate synthase (approx. 4000 units), $0.1 \mathrm{mmol}$ acetyl-CoA.

\section{Procedure}

$2 \mathrm{ml}$ of substrate solution is pipetted into the cell and the blank tracing is recorded. Then $0.1 \mathrm{ml}$ of serum is added, and the test tracing is recorded, everything proceeding analogously to the preceding determinations. Figure 4 shows an example of the determination of aspartate aminotransferase activity.

\section{Results}

We determined choline esterase (EC 3.1.1.8) activity in the sera of 30 men and 30 women, reporting for health checks, and manifesting no pathological symptoms. The values for other biochemical parameters were within our normal limits. Cholinesterase values were:

$$
\begin{aligned}
& \text { - men } 73.9, \mathrm{~s} \pm 10.3 \mu \mathrm{kat} / \mathrm{l}=4430, \mathrm{~s} \pm 610 \mathrm{U} / \mathrm{l} \\
& \text { - women } 71.1, \mathrm{~s} \pm 10.2 \mu \mathrm{kat} / \mathrm{l}=4270, \mathrm{~s} \pm 610 \\
& \\
& \mathrm{U} / \mathrm{l} \text {. }
\end{aligned}
$$

For a limited number of 20 other persons we compared our results with the Boehringer BiochemicaTest-Combination, Cholinesterase, Best. Nr. 15984; 
the coefficient of correlation was $r=0.9543$, the significance $t=13.919$ versus the table value 2.845 , probable error of coefficient of correlation $\eta= \pm 0.0135$.

The values of alkaline phosphatase and aspartate aminotransferase activities also correlated well with values from the routine methods.. For the evaluation of adenosyl-homocysteinase, clinical data determined by other methods are lacking. We considered using the changes occurring in haemopathies for comparison of methods, but the difficulty of obtaining special reagents rendered unfeasible the statistical evaluation of samples by the additional methods.

\section{Discussion}

Our equipment is purely experimental. For a final design we intend to use the electrode MME Metrohm, which dispenses with the classical cell containing mercury. Up to the present we have found the dropping electrode quite suitable, and it does not interfere with the enzyme activity. Another possibility is the utilization of a universal mercury mini- and microelectrode (5), making possible analyses of samples of a few microlitres, and being completely harmless with respect to hygiene at the work place. It would be very useful to replace the recorder by a digital display, which, on setting of an appropriate factor, would directly indicate the enzyme activity.

We also conducted routine determinations of choline esterase activity for clinical purposes, and, in accordance with the literature, found low values in hepatic cirrhosis and high values in hyperthyroidism. Our provisional normal range compares well with the data published in the literature. Szasz (6), with an analogous substrate and colorimetric measurement at $25^{\circ} \mathrm{C}$, gives normal ranges of $2200-5000 \mathrm{U} / 1$ for men, and $1800-4600 \mathrm{U} / 1$ for women. Our values lie within these ranges.

In addition to the described methods we have proposed further applications of the system, but have been able to demonstrate the feasibility of only some of them. The activity of alanine aminotransferase (EC 2.6.1.2) can be determined by the following sequential reactions:

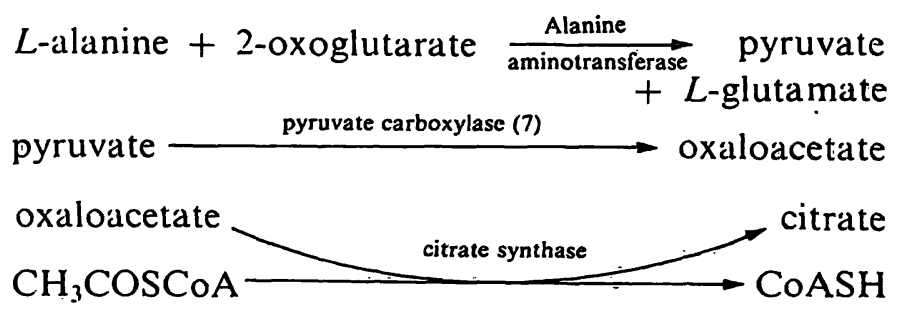

The activity of lactate dehydrogenase (EC 1.1.1.27) can be determined by the following sequential reactions:
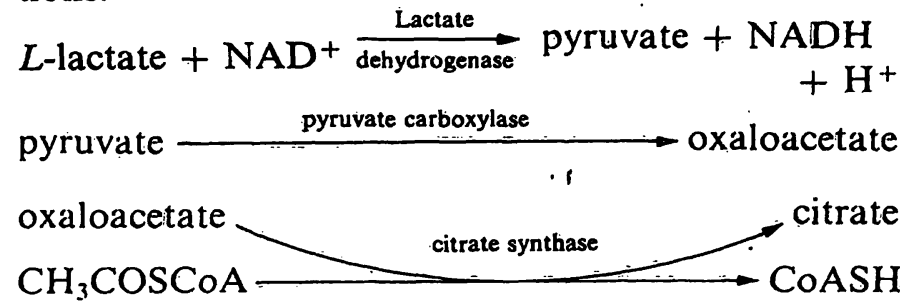

The activity of lipase (EC 3.1.1.3) can be determined by the reactions:

triolein $+\mathrm{H}_{2} \mathrm{O} \longrightarrow 3$ oleic acid oleic acid + ATP + CoASH $\stackrel{\text { acyl-CoA synthetase }}{\longrightarrow}$

$$
\text { oleyl-CoA + AMP + pyrophosphate, }
$$

when the CoASH consumption is measured. The photometric method is considerably more complicated with two additional sequential enzymic reactions (8).

Analogously the activities of phospholipases $A\left(A_{1}\right.$, EC 3.1.1.32, $\mathrm{A}_{2}, \mathrm{EC}$ 3.1.1.4), which cleave the fatty acid from, e.g. phosphatidylcholine, can be determined according to the preceding scheme. Again, this represents a simplification, compared with the described photometric method (9).

The concentration of a substrate, e.g. acetate, in the serum can be determined by the reaction:

$$
\begin{aligned}
& \text { acetate }+\mathrm{ATP}+\mathrm{CoASH} \stackrel{\text { acetyl-CoA synthetase }}{\longrightarrow} \\
& \mathrm{CH}_{3} \mathrm{COSCOA}+\mathrm{AMP}+\text { pyrophosphate, }
\end{aligned}
$$

in which the CoASH consumption is measured. The photometric method is more complicated with two additional sequential enzyme reactions (10).

Another example is the determination of carnitine concentration by the reaction:

$$
\begin{gathered}
L \text {-carnitine }+\mathrm{CH}_{3} \mathrm{COSCoA} \underset{\text { O-acetylcarnitine }+{ }^{\prime} \mathrm{CoASH}}{\stackrel{\text { carnitine acetyltransferase }}{\longrightarrow}} \\
.
\end{gathered}
$$

A photometric method with a further coupled reaction has also been described for carnitine (11).

The present results show that the described reactions permit the monitoring of changes in thiol group concentrations in various enzyme reactions, and also in some substrates.

Consultation of the Enzyme Nomenclature (12) shows that in enzyme reactions CoA can be used $77 \times$, glutathione $7 \times$, cysteine and homocysteine $14 \times$, lipoate $1 \times$, adenosyl- and ribosylhomocysteine 
$35 \times$. The products of enzyme reactions which can be exploited as substrates of coupled enzyme systems are encountered as follows: pyruvate $25 \times$, oxaloacetate $14 \times$, alanine and aspartate $14 \times$, acetate and carnitine $12 \times$.

Moreover, suitable synthetic substrates can be prepared whose enzymatic cleavage exposes a thiol group.

This approximate enumeration, of course, does not exclude further possibilities of combining enzyme reactions and utilizing this system at different potentials for the detection of many additional electrochemically active organic function groups, more than $\mathbf{3 0}$ of which are currently known. For these reasons we consider that the system has wide possibilities for further development. Already at the present time

\section{References}

1. Fišerová-Bergerová, V. (1962) Collection Czechoslov. Chem. Commun. 27, 693-700.

2. Homolka, J. (1971) Polarography of Proteins, Analytical Principles and Applications in Biological and Clinical Chemistry, in: Methods of Biochemical Analysis, Interscience Publishers, New York-London-Sydney-Toronto, 19, 435- 555

3. Homolka, J. (1977) Czechoslovak patent No. 19420022, applied for on 20 Dec. 1977.

4. Homolka, J. (1985) Czechoslovak patent No. 248348, applied for on 13 Apr. 1985.

5. Novotný, L. (1980) Czechoslovak patent No. 220439, applied for on 4 Apr. 1980. there exists a real possibility of determining at least 199 types of enzyme activities.

We publish this preliminary communication in the hope that the suggested potential applications will arouse the interest of other authors, and lead to the elaboration and optimalization of these methods and their verification on a wider scale.

\section{Acknowledgement}

The author is indebted to Dr. A. Holý, Czechoslovak Academy of Sciences, for the gift of substrate for the determination of alkaline phosphatase activity, and for suggesting the determination of adenosylhomocysteinase activity and providing the substrate. Thanks are also due to Dr. M. Heyrovský, Institute of Physical Chemistry, Czechoslovak Academy of Sciences, for expert advice, and to Mrs. $V$. Hodrmentová and Mrs. $M$. Angerová for technical assistance.
6. Szasz, G. (1968) Clin. Chim. Acta 19, 191-204.

7. Seubert, W. \& Remberger, U. (1961) Biochem. Z. 334, $401-414$

8. Hoffmann, G. E., Neumann, U., Hoffmann, S., Kaspar, P. \& Weiss, L. (1986) Clin. Chem. 32, 545-547.

9. Hoffmann, G. E., Schmidt, D., Bastian, B. \& Guder, W. G. (1986) J. Clin. Chem. Clin. Biochem. 24, 871-875

10. Bartelt, U. \& Kattermann, R. (1985) J. Clin. Chem. Clin. Biochem. 23, 879-881.

11. Peter, G. \& Haubitz, I. (1987) Lab. Med. 11, 134-141.

12. Enzyme Nomenclature, Elsevier Scientific Publishing Comp., Amsterdam 1973.

Prof. MUDr. J. Homolka, DrSc.

Zelinárská 14

ČS-14700 Praha 4 
